\title{
Skin-Gut Axis in Psoriasis Setting and Plan for Action: The Effect of Probiotics Supplementation On Clinical Outcomes, Metabolic Endotoxemia, Inflammation, and Cardiovascular Risk in Patients with Psoriasis
}

Jalal Moludi ( $\nabla$ jmoludi@yahoo.com )

Kermanshah University of Medical Sciences https://orcid.org/0000-0002-8333-414X

\section{Hamed Khedmatgozar}

Texas A\&M University College Station

\section{Fatemeh Pourteymour Fard Tabrizi}

Tabriz University of Medical Sciences Faculty of Dentistry

Hamidreza Razmi

Tabriz University of Medical Sciences

Mehdi Amirpour

Tabriz University of Medical Sciences

Pourya Fathi

Tabriz University of Medical Sciences

\section{Research}

Keywords: Skin-Gut Axis, Psoriasis, Probiotics, Inflammation, Cardiovascular Risk

Posted Date: July 24th, 2020

DOI: https://doi.org/10.21203/rs.3.rs-45348/v1

License: (c) (i) This work is licensed under a Creative Commons Attribution 4.0 International License.

Read Full License 


\section{Abstract}

Objective: Studies have proposed a link between psoriasis and an imbalanced gut microbiome. Therefore, the modulation of the gut microbiota with probiotics may improve clinical outcomes, metabolic endotoxemia, chronic inflammation, and cardiovascular risk factors in patients with psoriasis.

Methods: Forty-six patients with psoriasis randomized into two groups, group 1 received a twice a day capsule having freeze-dried powder with $1.6 \times 10^{9} \mathrm{CFU}$ for eight weeks, and group 2 received placebo. For clinical outcomes, we used the Psoriasis Area and Severity Index (PASI), blood pressure, and SF36 to measure the quality of life. And for biochemistry analysis, we measured pro-inflammatory cytokines (hsCRP and IL1- $\beta$ ), lipopolysaccharides (LPS), and lipid profile. All the data collected at baseline and the end of the study.

Results: Forty-six patients (28 [60\%] female; mean [SD] age, 42.51 [14.55] years) contributed to the study. Improvements in SF36 score as an indexed for the QOL was significant in patients taking probiotics supplementation comparing to the placebo group and PASI $(-5.06 \pm 2.10$ vs. $0.30 \pm 1.80, P=0.049)$ as well. After the intervention, the treatment group had significant reductions in LDL and TC compared to the placebo group. In addition, we observed a considerable reduction in serum LPS levels (-7.21 $\pm 10.33 \mathrm{vs}$. $-2.74 \pm 0.97 \mathrm{mmol} / \mathrm{L}, P=0.010)$, hs-CRP levels $(-1.67 \pm 0.95$ vs. $-0.70+0.38 \mathrm{mg} / \mathrm{L}, P=0.013)$, and IL $1-\beta$ levels $(-1.64 \pm 1.10$ vs. $0.17+-0.20 \mathrm{mg} / \mathrm{L}, \mathrm{P}=0.043)$ in the probiotics group.

Conclusion: This study shows that probiotics significantly improved the quality of life and seriousness in psoriatic patients. Moreover, it enhances cardiovascular risk factors and inflammatory/oxidative stress markers.

Trial registration: This trial also was recorded in the Iranian registry of clinical trials (https://www.irct.ir) (code: IRCT20191124045483N1).

\section{Introduction}

Recent studies revealed the importance of gut microbiota in body health conditions [1]. Understanding of the gut microbiome started a new field of study which emphasizes the potential biochemical mechanisms of the healthy gut to local and distant organ diseases [2]. The relationship of the gut to the skin, as the gut-skin axis, is a new area of investigation [1]. The gut and skin are both complex immune and neuroendocrine organs, and each has a community of microbes that addresses the physiology of their local atmospheres [3]. Gut and skin interact, each one affecting the other through several pathways, especially the microbiome and its metabolites [1]. A modification in the gut microbiota (dysbiosis) is related to type 2 diabetes, obesity, atopy, and cardiovascular disease.

Additionally, the relationship between dysbiosis and their possible role in the pathogenesis of skin conditions, including psoriasis, rosacea, and acne, has been shown. Still, it needs to be studying more to complete an understanding of these disorders. [4]. Also, some gastrointestinal disorders can present with 
dermatological skin findings. For instance, Celiac diseaselinks to skin manifestations, such as erythema and oral lesions [5] and, psoriasis is more prevalent in patients with Crohn's disease compared to healthy people [6].

The positive effects of gut bacteria on skin health and appearance determined in previous animal and human studies [1, 4]. As far as we know, no previous research has investigated the effect of probiotics supplementation in patients with psoriasis.

Psoriasis has long been observed as an immune-mediated chronic inflammatory disease with impairment in psychologic and emotional daily physical functioning and decreased quality of life (QOL) [7]. Regardless of the extensive use of several drugs, including infliximab (Remicade) and etanercept, the treatment is still unacceptably poor [8]. So it is necessary to find different ways to cure the disease. Psoriasis is a complex, chronic, inflammatory, multifactorial disease that involves hyper-proliferation of the keratinocytes in the epidermis [9]. Interestingly, patients with psoriatic arthritis are at higher risk of CVD[10] and have subclinical evidence of gut inflammation, and endotoxemia increased LPS in blood circulation [1]. There is an indirect communication between the skin and the gut microbiota, and dysbiosis may contribute to the development of psoriasis [4]. Besides, previous studies have shown that probiotics improved pro-inflammatory markers and metabolic endotoxemia in many clinical conditions [11]. However, there are no clinical assessments in patients with psoriasis.

Probiotics are live microorganisms, which, by sufficient consumption, affects the host's health. The bacterial probiotic studies revealed to exert valuable effects on skin health. Probiotics effect the manipulation of the immune system and the reduction of endotoxemia [11].

Now, the recommendation of oral probiotics as a management or adjuvant approach in skin disease is not usual. Dysbiosis usually observed in psoriasis. The crosstalk between gut microbiota and skin could provide a reasonable mechanism with understandable therapeutic potential in psoriasis. Considering the immune-regulatory, and anti-inflammatory effects of probiotics $[2,3,11]$, we aimed to determine the probable consequences of probiotics supplementation on clinical outcomes, metabolic endotoxemia, chronic inflammation and cardiovascular risk factors in psoriasis' patients.

\section{Methods}

Forty-eight adults, with moderate to severe psoriasis, were participated in this randomized, double-blind, placebo-controlled trial. This study was carried out at the dermatology clinics of affiliated Tabriz University of Medical Sciences (TBZMED), Iran, from December 2019 to January 2020. Patients referred with the diagnosis of psoriasis classified for contribution in the study and assessed by a dermatologist to make sure they have inclusion criteria.

Patients were involved as recent-onset psoriasis of the skin and never preserved with systemic diseasemodifying anti-rheumatic drugs (DMARDs; oral, biologic agents, or steroids. Patients were excluded if they refused to participate or use of any current unusual diet (e.g., macrobiotic diet), probiotics and antibiotic 
supplements, or if they had an autoimmune disease, like IBD, or inflammatory arthritis. An unaware observer who was blind to the survey provided the random allocation. Participants stratified and block randomized based on disease stage, age, sex, and BMI. After 12 hours fasting, the blood sample was collected and supplements handed to the participants. The intervention length was eight weeks. Written consensus attained from patients. This research procedure accepted by an official review board of TBZMED (IR.TBZMED.REC.1398.916). This trial also was recorded in the Iranian registry of clinical trials (https://www.irct.ir) (code: IRCT20191124045483N1).

\section{Study design}

A double-blind trial at two levels (researchers, patients), single-center, parallel-group, randomized, placebocontrolled has been designed to determine the effect of probiotic supplementation on patients with psoriasis. A computer generated list of random blocks to make sure cover-up of allocation to both participants and investigators. Patients were assigned to receive on probiotics $(n=23)$ or placebo $(n=23)$ capsules for eight weeks. The probiotic capsule contains multi-strain at least $1.6 \times 109 \mathrm{CFU} / \mathrm{g}$ of probiotics including (Lactobacillus acidophilus, Bifidobacterium bifidum, Bifidobacterium lactis and Bifidobacterium langum) for 8 weeks from TacZist Co. Iran. Both placebo (which received maltodextrin capsules) and the supplement used twice a day with dinner and lunch.

\section{Efficacy assessments}

Quality of life was measured using The Short Form (36) Health Survey, which is a 36-item, patientreported survey of patient health. The SF-36 (range 25-100; higher scores representing worse impairment) is a measure of health status and, is commonly used in health economics as a variable in the quality-adjusted life year calculation to determine the effectiveness of a health treatment. The SF 36 showed a valid indicator of the QOL with respectable properties (Cronbach's alpha $=0$.92) [12].

The primary goal of this survey was to evaluate the psoriasis Area and Severity Index (PASI). PASI is the best generally used instrument for the quantity of severity of psoriasis. PASI combines the assessment of the severity of plaque and the area affected by a single score in the range 0 (no disease) to 72 (severe disease) [13]. To measure the PASI, the body surface separates into four different regions - the severity estimate by three clinical signs: erythema (redness), induration (thickness), and desquamation (scaling) in this area. Severity parameters measured on a scale of 0 to 4 , none to the maximum. PASI widely use in clinical trials for the treatment of psoriasis, and changes in total PASI scores represent the efficacy and outcomes. PASI, usually presented as a percentage response rate, e.g., PASI 50, PASI 75. PASI 75, for instance, represents the percentage (or number) of patients who have achieved a $75 \%$ or more reduction in their PASI score from baseline [14].

\section{Assessment of anthropometric}


Bodyweight was weighed via a scale with $0.250 \mathrm{~kg}$ accuracy (Seca, Hamburg, Germany) while wearing light clothing and without shoes. Height was measured by a tape with $0.5-\mathrm{cm}$ accuracy without shoes. BMl defines as dividing weight $(\mathrm{Kg})$ in height ${ }^{2}(\mathrm{~m})$.

\section{Biochemical variables}

Blood samples were taken after a 12-hours fasting serum and whole blood divided by centrifugation. Immunoturbidimetry methods measured High-sensitivity C-reactive protein (hs-CRP) levels. Serum levels of Interleukin 6 (IL1-Beta) and lipopolysaccharides (LPS) analyzed by commercial Enzyme-Linked Immunosorbent Assay (ELISA) kits (Crystal Chem, China).

\section{Statistical analysis}

We run an SPSS software (version 16; SPSS Inc., Chicago, IL), and findings presented as mean \pm SD. The normal distribution of variables measured by skewness and kurtosis test. The primary outcome for the current study was the change in PASI score, with and without adjustment for confounder factors. Withingroup comparisons (end-point vs. baseline) was undertaken by paired samples t-test. To adjust for potential confounders, we provide analysis of covariance (ANCOVA). A p-value of less than 0.05 (typically $\leq 0.05$ ) is statistically significant. And we used the chi-square test to analyze mean changes in PASI 50 and PASI 75 intervention versus placebo.

\section{Results}

A total of 50 participants enrolled, and 46 (92\%) of them finished the study [Figure 1, CONSORT diagram]. Compliance assessed by pill-count and factors affecting the adherence to the survey by patients' reports during phone call sessions, which were more than $90 \%$ of capsules in both groups. Baseline characteristics, including anthropometric indices, dietary intakes, physical activity levels, family history of psoriasis, duration of psoriasis, and age, were well balanced across the two arms (Table 1). None of the participants show any adverse effects. 
Table 1

bassline of patient characteristics

\begin{tabular}{|c|c|c|c|}
\hline Variable & $\begin{array}{l}\text { Probiotic group } \\
(\mathrm{n}=23)\end{array}$ & $\begin{array}{l}\text { Placebo group } \\
(n=23)\end{array}$ & P-value \\
\hline Age (years) $^{a}$ & $42.04 \pm 8.10$ & $43.76 \pm 8.86$ & 0.644 \\
\hline Weight $(\mathrm{kg})^{\mathrm{b}}$ & $66.84 \pm 13.43$ & $64.66 \pm 14.10$ & 0.749 \\
\hline BMI & $27.02 \pm 6.58$ & $26.80 \pm 4.44$ & 0.818 \\
\hline WC (cm) & $96.72 \pm 14.42$ & $94.76 \pm 17.16$ & 0.198 \\
\hline Calorie intake (Kcal/d) & $1870.35(135.6)$ & $1743.1(131.3)$ & 0.108 \\
\hline Sex & & & 0850 \\
\hline Female $n(\%)$ & $13(56)$ & $15(65)$ & \\
\hline Family history of psoriasis $\mathrm{n}(\%)$ & $5(20)$ & $3(20)$ & 0.935 \\
\hline Duration of psoriasis (years) ${ }^{a}$ & $1.88(0.77)$ & $2.01(1.01)$ & 0.665 \\
\hline Smoking n(\%) & $3(12)$ & $5(20)$ & 0.455 \\
\hline PAL (MET) & $4576.01(1200.11)$ & $4125(1700.33)$ & $0.544^{c}$ \\
\hline $\begin{array}{l}\text { PAL: Physical activity Levels, BN } \\
\text { a- Values are expressed as mear } \\
\text { b- Values are expressed as frequ } \\
\text { c- Chi-square test } \\
\text { d- Independent samples t-test }\end{array}$ & $\begin{array}{l}\text { Body mass index, W } \\
\text { SD) } \\
\text { cy (\%) }\end{array}$ & Waist circumfere & nce. \\
\hline
\end{tabular}

\section{Post-intervention}

Table 2 shows the results of pre- and post-intervention scores on the PASI and SF36 scores in both groups. After 8-weeks intervention, the subjects who took the probiotic supplements had considerably higher reductions in PASI scores as compared to the placebo group $(-5.06 \pm 2.10$ vs. $0.30 \pm 1.80, P=$ 0.049).

Improvements in QOL as indexed by SF36 score were higher in patients taking probiotics supplementation in comparison of the placebo group (-19.10 \pm 3.1 vs. $13.30 \pm 5.6, P=0.034)$ (Table 2). PASI 50 and 75 implies the number of patients who have achieved a $75 \%$ and 50 and more decrease in their PASI score from baseline, respectively. We obtain good results with this method. Our results revealed that 12 patients (40\%) reached PASI 50 and 4 had achieved PASI 75 in the probiotic group, whereas in the 
placebo group, 5\% attained PASI 50 and 2 produced PASI 75. The probiotics group had statically significantly higher PASI 50 improvement than the placebo group $(p=0.048)$, but not PASI 75. (Fig. 2$)$.

Table 2.

Effect of probiotic supplementation on Psoriasis Area and Severity Index and Quality of life (using The Short Form 36) score

\begin{tabular}{|c|c|c|c|}
\hline Variable & $\begin{array}{l}\text { Probiotic group } \\
(n=23)\end{array}$ & $\begin{array}{l}\text { Placebo group } \\
(n=23)\end{array}$ & MD (95\% Cl), P-value \\
\hline \multicolumn{4}{|l|}{ PASI (total score) } \\
\hline Before & $10.66(7.14)$ & $10.91(8.45)$ & $\begin{array}{l}0.07 \text { (-5.3 to } 5.67), 0.998 \\
\mathrm{a}\end{array}$ \\
\hline After & $5.33(5.45)$ & $11.72(8.7)$ & $\begin{array}{l}-5.45(-10.8 \text { to }-0.07) \\
\mathbf{0 . 0 4 9} \text { b }\end{array}$ \\
\hline MD (95\% Cl), P-value & $\begin{array}{l}-5.6(-9.3 \text { to }-0.75), \\
\mathbf{0 . 2 4}\end{array}$ & $\begin{array}{l}0.30(-3.1 \text { to } 3.97) \\
0.532\end{array}$ & \\
\hline $\begin{array}{l}\text { PASI } 50 \text { (number of } \\
\text { patients) }\end{array}$ & 12 & 5 & 0.048 \\
\hline $\begin{array}{l}\text { PASI } 75 \text { (number of } \\
\text { patients) }\end{array}$ & 4 & 2 & 0.264 \\
\hline \multicolumn{4}{|l|}{ SF36 } \\
\hline Before & $81.58(15.33)$ & $78.48(19.8)$ & $\begin{array}{l}3.10(-7.5 \text { to } 6.1), 0.609 \\
\text { a }\end{array}$ \\
\hline After & $61.74(16.70)$ & $67.18(14.7)$ & $\begin{array}{l}-9.87(-17.03 \text { to }-0.2 .1) \\
0.034^{\text {b }}\end{array}$ \\
\hline MD (95\% Cl), P-value & $\begin{array}{l}-19.10(-10.8 \text { to }-4.6 .) \\
0.002\end{array}$ & $\begin{array}{l}-13.30(-11.7 \text { to } 11.1) \\
0.288\end{array}$ & \\
\hline \multicolumn{4}{|c|}{$\begin{array}{l}\text { Values are expressed as mean (SD), SF36: The Short Form } 36 \text {, PASI: Psoriasis Area and Severity } \\
\text { Index, PASI 75: the percentage (or number) of patients who have achieved a } 75 \% \text { or more reduction in } \\
\text { their PASI score from baseline. }\end{array}$} \\
\hline \multicolumn{4}{|c|}{ a- Independent samples t-test } \\
\hline \multicolumn{4}{|c|}{$\begin{array}{l}\text { b- Adjusted for baseline values and energy intake changes using the analysis of covariance (ANCOVA) } \\
\text { test }\end{array}$} \\
\hline c- Paired-samples t-test & & & \\
\hline
\end{tabular}

\section{Effect of probiotic on cardiovascular risk factors}


After two months of probiotics supplementation, after adjusting possible confounding factors, changes in total cholesterol and LDL-C were not significant, also no considerable difference in other metabolic risk factors observed within groups. Overall, a substantial reduction in serum TC $(-31.7 \pm 35.83$ vs. $-5.7 \pm$ $31 \mathrm{mmol} / \mathrm{L}, \mathrm{P}=0.037)$, and LDL-C concentrations (-26.62 \pm 35.7 vs. $-5.44+40.1 \mathrm{mg} / \mathrm{L}, \mathrm{P}=0.048)$, were noticed subsequent the supplementation with probiotics, compared to the placebo. Consequently, taking probiotics to lead to a significant reduction in some cardiovascular risk factors in psoriatic patients (Table 3). 
Table 3

Effect of probiotics supplementation on cardiovascular risk factor (including FBS, Lipid Profile and blood pressure) in psoriatic patients

\begin{tabular}{|c|c|c|c|}
\hline Variable & $\begin{array}{l}\text { Probiotic group } \\
(n=23)\end{array}$ & $\begin{array}{l}\text { Placebo group } \\
(n=23)\end{array}$ & MD (95\% Cl), P-value \\
\hline \multicolumn{4}{|l|}{ FBS $(\mathrm{mg} / \mathrm{dL})$} \\
\hline Before & $119.15(26.1)$ & $108.31(28.3)$ & $\begin{array}{l}-10.7(-10.4 \text { to } 12.8) \\
0.461^{a}\end{array}$ \\
\hline After & $102.14(13.7)$ & $100.30(24.4)$ & $\begin{array}{l}1.68 \text { (-5.8 to } 10.7), 0.781 \\
b\end{array}$ \\
\hline $\begin{array}{l}\text { MD }(95 \% \mathrm{Cl}), \mathrm{P}- \\
\text { value }^{\mathrm{c}}\end{array}$ & $\begin{array}{l}-17.01 \text { (-35.6 to } 9.8), \\
0.194\end{array}$ & $\begin{array}{l}-8.31(-18.9 \text { to } 2.9) \text {, } \\
0.146\end{array}$ & \\
\hline \multicolumn{4}{|c|}{ Total cholesterol (mg/dl) } \\
\hline Before & $167.1(28.02)$ & $176.1(41.8)$ & $\begin{array}{l}-9.12(-29.58 \text { to } 12.5), \\
0.394^{\text {a }}\end{array}$ \\
\hline After & $139.7(32.6)$ & 168. 9 (46.3) & 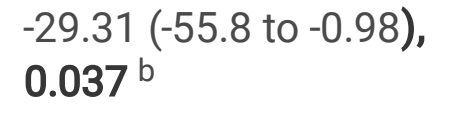 \\
\hline $\begin{array}{l}\text { MD }(95 \% \mathrm{Cl}), \mathrm{P}- \\
\text { value }^{\mathrm{c}}\end{array}$ & $\begin{array}{l}-31.7(-53.11 \text { to }-7.74), \\
\mathbf{0 . 0 1 8}\end{array}$ & $\begin{array}{l}-5.9(-34.01 \text { to } 22.1) \\
0.593\end{array}$ & \\
\hline \multicolumn{4}{|l|}{ TG (mg/dl) } \\
\hline Before & $173.7(46.4)$ & $160.41(58.9)$ & $\begin{array}{l}12.20 \text { (-29.2 to } 35.7), \\
0.425^{\text {a }}\end{array}$ \\
\hline After & $153.9(56.3)$ & $152(55.1)$ & $\begin{array}{l}1.91 \text { (-32.0 to } 36.85), \\
0.861^{\text {b }}\end{array}$ \\
\hline $\begin{array}{l}\text { MD }(95 \% \mathrm{Cl}), \mathrm{P}- \\
\text { value }^{\mathrm{c}}\end{array}$ & $\begin{array}{l}-13.85(-34.2 \text { to } 6.53) \\
0.428\end{array}$ & $\begin{array}{l}-13.43(-50.4 \text { to } 23.5) \\
0.633\end{array}$ & \\
\hline \multicolumn{4}{|l|}{$\mathrm{LDL}(\mathrm{mg} / \mathrm{dl})$} \\
\hline Before & $91.54(31.68)$ & $102.75(43.4)$ & $\begin{array}{l}-7.19(-30.54 \text { to } 16.14) \\
0.537 \text { a }\end{array}$ \\
\hline After & $70.60(40.7)$ & $86.21(47.9)$ & $\begin{array}{l}25.45(-53.25 \text { to } 2.34) \\
0.048{ }^{\text {b_ }}\end{array}$ \\
\hline $\begin{array}{l}\text { MD }(95 \% \mathrm{Cl}), \mathrm{P}- \\
\text { value }^{\mathrm{c}}\end{array}$ & $\begin{array}{l}-26.62(-48.16 \text { to }-2.02) \\
\mathbf{0 . 0 9 0}\end{array}$ & $\begin{array}{l}-5.44(-35.76 \text { to } 24.8) \\
0.664\end{array}$ & \\
\hline
\end{tabular}




\begin{tabular}{|c|c|c|c|}
\hline Variable & $\begin{array}{l}\text { Probiotic group } \\
(n=23)\end{array}$ & $\begin{array}{l}\text { Placebo group } \\
(n=23)\end{array}$ & MD (95\% Cl), P-value \\
\hline Before & $42.77(4.89)$ & $44.59(7.4)$ & $\begin{array}{l}-1.81 \text { (-1.88 to } 4.05) \\
0.778^{\text {a }}\end{array}$ \\
\hline After & $43(4.7)$ & $44.2(9.1)$ & 0.54 (-5.2 to 2.7$), 0.413^{b_{-}}$ \\
\hline $\begin{array}{l}\text { MD }(95 \% \mathrm{Cl}), \mathrm{P}- \\
\text { value }^{\mathrm{c}}\end{array}$ & $\begin{array}{l}2.09(-0.54 \text { to }-4.7) \\
0.114\end{array}$ & $\begin{array}{l}2.17(-2.44 \text { to } 6.7), \\
0.209\end{array}$ & \\
\hline \multicolumn{4}{|l|}{ DBP $(\mathrm{mmHg})$} \\
\hline Before & $83.49(10.9)$ & $78.26(13.9)$ & $\begin{array}{l}5.64 \text { (-3.03 to } 12.33) \\
0.747 \text { a }\end{array}$ \\
\hline After & $79.48(7.6)$ & 77.7 (13.7) & $\begin{array}{l}2.52 \text { (-1.3 to }-0.3), 0.319 \\
b_{-}\end{array}$ \\
\hline $\begin{array}{l}\text { MD }(95 \% \mathrm{Cl}), \mathrm{P}- \\
\text { value }^{\mathrm{c}}\end{array}$ & $\begin{array}{l}-4.01 \text { (-8.8 to } 0.26) \text {, } \\
0.051\end{array}$ & $\begin{array}{l}-0.47 \text { (-3.8 to } 2.8) \\
0.197\end{array}$ & \\
\hline \multicolumn{4}{|l|}{ SBP $(\mathrm{mmHg})$} \\
\hline Before & $131.4(13.6)$ & 124.74 (12.99) & $\begin{array}{l}5.73 \text { (-4.1 to } 17.78), 0.266 \\
a\end{array}$ \\
\hline After & $121.7(13.8)$ & $120.3(14.84)$ & $\begin{array}{l}1.12 \text { (-8.7 to } 6.41), 0.986 \\
b_{-}\end{array}$ \\
\hline $\begin{array}{l}\text { MD }(95 \% \mathrm{Cl}), \mathrm{P}- \\
\text { value }^{\mathrm{c}}\end{array}$ & $\begin{array}{l}-10.6(-14.08 \text { to }-1.4), \\
0.019\end{array}$ & $\begin{array}{l}-4.43(-9.74 \text { to } 4.87), \\
0.456\end{array}$ & \\
\hline $\begin{array}{l}\text { MD: mean differe } \\
\text { lipoprotein, TG: TI } \\
\text { pressure, Values a } \\
\text { a- Independent sa } \\
\text { b- Adjusted for ba } \\
\text { test } \\
\text { c- Paired-samples }\end{array}$ & $\begin{array}{l}\text { FBS: Fasting blood gl } \\
\text { ceride, TC: Total chole } \\
\text { expressed as mean (SD } \\
\text { les t-test } \\
\text { ine values, weight, and } \\
\text { est }\end{array}$ & $\begin{array}{l}\text { e, HDL: high density lip } \\
\text { I, SBP: Systolic blood }\end{array}$ & $\begin{array}{l}\text { tein; LDL: low density } \\
\text { ure, DBP: diastolic blood } \\
\text { s of covariance (ANCOVA) }\end{array}$ \\
\hline
\end{tabular}

\section{Effect on endotoxemia and inflammation}

A considerable reduction observed in serum LPS levels $(-7.21 \pm 10.33$ vs. $-2.74 \pm 0.97 \mathrm{mmol} / \mathrm{L}, P=0.010)$, hs-CRP levels $(-1.67 \pm 0.95$ vs. $-0.70+0.38 \mathrm{mg} / \mathrm{L}, \mathrm{P}=0.013)$, and IL 1 -Beta levels $(-1.64 \pm 1.10$ vs. $0.17+$ $-0.20 \mathrm{mg} / \mathrm{L}, \mathrm{P}=0.043)$ in probiotic supplementation compare to placebo group. In sum, the current results 
approve that probiotics supplementation results in a significant reduction in the biomarker of inflammation and endotoxemia compared to the placebo (Table.4).

Table 4

Effect of probiotic supplementation on Hs-CRP, IL1-Beta and LPS Levels

\begin{tabular}{|c|c|c|c|}
\hline Variable & $\begin{array}{l}\text { Probiotic group } \\
(n=23)\end{array}$ & $\begin{array}{l}\text { Placebo group } \\
(n=23)\end{array}$ & MD (95\% Cl), P-value \\
\hline \multicolumn{4}{|l|}{ Hs-CRP } \\
\hline Before & $2.87(1.34)$ & $2.72(1.45)$ & $-.15(-0.87$ to 1.67$), 0.766$ \\
\hline After & $1.20(0.45)$ & $2.02(0.70)$ & $\begin{array}{l}-0.87(-1.38 \text { to }-0.17) \\
\mathbf{0 . 0 1 3}\end{array}$ \\
\hline $\begin{array}{l}\text { MD }(95 \% \mathrm{Cl}), \mathrm{P}- \\
\text { value }^{\mathrm{c}}\end{array}$ & $\begin{array}{l}-1.67(-9.3 \text { to }-0.75) \\
0.001\end{array}$ & $\begin{array}{l}0.70(-3.1 \text { to } 3.97) \\
0.111\end{array}$ & \\
\hline \multicolumn{4}{|l|}{ IL1-Beta } \\
\hline Before & $5.17(1.8)$ & $5.51(1.25)$ & $4.55(-13.5$ to 3.1$), 0.657^{a}$ \\
\hline After & $3.53(0.95)$ & $5.31(0.87)$ & $\begin{array}{l}-1.77(-3.52 \text { to }-0.80), \\
\mathbf{0 . 0 4 3}^{\text {b }}\end{array}$ \\
\hline $\begin{array}{l}\text { MD }(95 \% \mathrm{Cl}), \mathrm{P}- \\
\text { value }^{\mathrm{c}}\end{array}$ & $\begin{array}{l}-1.64(-2.8 \text { to }-0.61 .), \\
0.003\end{array}$ & $\begin{array}{l}-0.20(-2.7 \text { to } 1.7), \\
0.829\end{array}$ & \\
\hline \multicolumn{4}{|l|}{ LPS } \\
\hline Before & $21.96(6.33)$ & $25.95(9.8)$ & $-0.33(-1.5$ to 1.1$), 0.286^{a}$ \\
\hline After & $15.74(5.70)$ & $23.21(8.7)$ & $\begin{array}{l}-7.47(-13.52 \text { to }-1.20) \\
\mathbf{0 . 0 1 0} \text { b }\end{array}$ \\
\hline $\begin{array}{l}\text { MD }(95 \% \mathrm{Cl}), \mathrm{P}- \\
\text { value }^{\mathrm{c}}\end{array}$ & $\begin{array}{l}-7.21(-10.8 \text { to }-4.6 .), \\
0.019\end{array}$ & $\begin{array}{l}-2.74(-11.7 \text { to } 11.1), \\
0.498\end{array}$ & \\
\hline
\end{tabular}

\section{Discussion}

The pathogenesis of psoriasis, an immune-mediated inflammatory skin disorder, is not entirely understandable. But, various studies demonstrated the strong correlation between gastrointestinal health and skin, particularly microbiome interaction with the immune system, which affects the pathophysiology of inflammatory situations $[1,4,7,8]$. In this regard, dietary factors, mainly, probiotics with significant modifying effect on the gut microbiome and thereby influence the inflammatory state, must be considered in therapeutic protocols. However, there is limited evidence on probiotic supplementation in psoriasis treatment; accordingly, this study designed to specify the probable therapeutic effects of 
probiotic supplementation in psoriatic patients. This study demonstrated that probiotics supplementation for eight weeks in psoriatic patients had a beneficial impact on improving QOL scores, disease severity, reduction of LDL, and total cholesterol levels, and attenuating inflammation cytokines/oxidative stress biomarkers.

Previous studies reported a positive linear correlation between the severity of psoriasis disease and its negative impact on the patient's life (health-related Quality of Life), workplace, and loss of productivity [6, $10,15]$. In this study, we defined that probiotic supplementation improved QOL scores in patients with psoriasis. Similarly, several probiotics supplementation studies in other diseases and situations have shown improvement in QoL scores of probiotic consumers $[16,17]$. The mechanisms behind this effect remain uncertain. It seems that modulation of the bacterial species in the gut via oral probiotics was associated with psychological status through gut microbiota-brain interaction and neuroactive potential of gut microbiota. The gut microbiome generates molecules with neuro-active functions as well as particles that influence human cells to produce neuroactive agents, So the psychiatric state and a sense of wellness could be affected by the gut microbiome [18]. Recently, it is documented that Butyrateproducing Faecalibacterium and Coprococcus bacteria were consistently associated with a higher quality of life indicators. Moreover, microbial synthesis substances have a potential rolein dopamine metabolite 3,4-dihydroxy phenylacetic acid, and a possible part of microbial $y$-aminobutyric acid production are correlated positively with mental quality of life [19].

Our data reveal that eight weeks' supplementation with probiotics improved the clinical outcomes of the psoriasis disease, which assessed by standardized index, PASI. Similarly, other studies [3, 20, 21] support this finding of the potential improvement effect of probiotic supplementation on psoriasis, and consequently, altering the gut microbiome. The gut-skin axis contributes to the involving mechanisms behind this effect. The generated neurotransmitters (dopamine, serotonin, GABA, and acetylcholine) by the intestinal microbiome cross the intestinal epithelium into the bloodstream to regulate skin functions, alter barrier function, hair growth and melatonin synthesis in the skin [1,3]. Moreover, it affects the production of short-chain fatty acids (SCFAs), in particular, butyrate It binds to G-protein-coupled receptors expressed on keratinocytes and endothelial and immune cells and inhibits inflammation through regulating the histone deacetylases activity, modulating the inflammatory NFKB signaling pathway, and promoting Treg accumulation in the skin $[3,20,21]$. Accordingly, it seems that modifying the gut microbiota by probiotics supplementation could be an important therapeutic option in psoriasis (Figure. 3).

Nowadays, the relationship between psoriasis and an increased incidence of cardiovascular diseases is well established [22]. Several studies confirmed that patients with psoriasis have a higher risk of developing severe cardiovascular events, such as stroke and myocardial infarction (MI) [10, 23]. The chronic inflammation which occurs in psoriasis accelerates involved systemic mechanisms in other chronic inflammatory diseases, including atherosclerosis [24, 25]. Regarding, systemic inflammation is considered the leading cause of CVD risk in psoriasis; our study aimed to evaluate the effect of eightweeks of probiotic supplementation on the inflammatory status of psoriatic patients. We found that this

Page $12 / 19$ 
intervention led to decrees MDA, IL-6, and hs-CRP levels in patients with psoriasis. Up to now, there are a few studies that investigate the role of probiotics supplementation in psoriasis. However, there is some evidence that probiotics may exert beneficial immunoregulatory effects by reducing inflammation [20, 26]. One study showed that oral administration of Lactobacillus pentosus GMNL-77 (as a probiotic), in a mouse model of psoriasis, reduced tumor necrosis factor- $a$ and IL-23-IL-17 axis cytokines, which was associated with significant decreased erythematous scaling lesions and epidermal thickening in comparison to untreated control mice [26]. Another study showed that Lactobacillus rhamnosus suppressed the expression of TNF-a, IL-6, and proinflammatory cytokines in the IL-23/IL-17 cytokine axis [27]. Our findings are in agreement with the previous study on severe pustular psoriasis cases; that did not respond to steroids, dapsone, and methotrexate. However, after beginning probiotic supplementation (Lactobacillus sporogenes) three times per day, the psoriatic patients showed significant clinical improvement within two weeks with almost complete remission after four weeks [29]. In a placebocontrolled study of psoriasis patients, Bifidobacterium Infantis supplementation for eight weeks led to significantly decreased plasma levels of inflammatory C-reactive protein and TNF- $\alpha$ in comparison with the placebo group [20]. The authors proposed that in response to probiotic supplementation, levels of the beneficial microbial inhabitant of the large intestine increased. These species are much less abundant in the gut of psoriatic patients than in healthy ones. Butyrate, an SCFA that provides energy for colonocytes, reduces oxidative stress, and exerts anti-inflammatory action by triggering regulatory $T$ cells, thereby conferring immune tolerance beyond the GI system $[1,3,24,28]$.

\section{Limitations}

There are several limitations to this RCT. First, the sample size is small, which restricts generalizability second. The period of the intervention was eight months, which is better to run long-term studies. Prolonged supplementation would be necessary to approve the beneficial effects of probiotics on psoriasis patients. Furthermore, the gut microbiota profiles not assessed in our study.

\section{Conclusion}

This study shows that eight-week probiotics supplementation results in significant improvements in psoriasis severity and patient-reported quality of life. Moreover, the daily consumption of probiotics for eight weeks had beneficial effects on improving the inflammatory and oxidative stress status, which is associated with psoriasis. In addition to the enhancement in psoriasis, it has been shown that there are many other reasons for psoriasis patients to use a probiotic supplementation. Psoriasis, particularly if uncontrolled, is related to an amplified risk of CVD, and probiotic supplementation may alleviate cardiovascular risk factors (e.g., decrease inflammation and oxidative stress). In conclusion, it seems that probiotic supplementation is helpful, and it would be beneficial to be a part of the treatment approach in patients with psoriasis. However, more studies are required to accurately assess the role of probiotics supplementation in psoriasis and investigate the mechanisms of the detected in the current study. 


\section{Declarations}

\section{Ethical Approval}

Our study was in agreement with the Helsinki Declaration of the World Medical Association (2000) and was accepted by our local ethics committee of Tabriz University of Medical sciences as a proposal for PhD grade in Nutritional Sciences (IR.TBZMED.REC.1397.184) and also was listed in the Iranian Registry of Clinical Trials (IRCT) (IRCT20121028011288N15).

\section{Informed Consent}

Informed consent was obtained from all individual participants included in the study using opt-out procedure.

\section{Consent for publication}

All authors support the submission to this journal.

\section{Availability of data and materials}

Data will be available upon request from the corresponding author. Also, Dr. Moludi Jalal as correspondent authors confirmed that full access to all the data in the study upon request and takes responsibility for the integrity of the data and the accuracy of the data analysis.

\section{Conflict of Interest}

The authors declare that there is no conflict of interest.

\section{Funding/Support}

This research was partially supported by Tabriz University of Medical sciences ((grant number 184).

\section{Acknowledgements}

We express thanks all members of current study group who providing understanding and expertise that greatly assisted the research. Also, we would like to thank the Student Research Committee, Tabriz University of Medical Science, for financial support. 


\section{Author contribution}

Moludi Jalal designed the study and has conducted the statistical analysis, Razmi Hamidrza completed the entire clinical studies, Mehdi Amirpour collected and analyzed the data. All of the other co-authors have accompanied to edit the manuscript.

\section{References}

1. O'Neill, C.A., et al., The gut-skin axis in health and disease: a paradigm with therapeutic implications. BioEssays, 2016. 38(11): p. 1167-1176.

2. Choct, M., Managing gut health through nutrition. British poultry science, 2009. 50(1): p. 9-15.

3. Salem, I., et al., The gut microbiome as a major regulator of the gut-skin axis. Frontiers in microbiology, 2018. 9: p. 1459.

4. Codoñer, F.M., et al., Gut microbial composition in patients with psoriasis. Scientific reports, 2018. 8(1): p. 1-7.

5. Greuter, T., A. Navarini, and S.R. Vavricka, Skin manifestations of inflammatory bowel disease. Clinical reviews in allergy \& immunology, 2017. 53(3): p. 413-427.

6. Wu, J.J., et al., The association of psoriasis with autoimmune diseases. Journal of the American Academy of Dermatology, 2012. 67(5): p. 924-930.

7. Griffiths, C.E. and J.N. Barker, Pathogenesis and clinical features of psoriasis. The Lancet, 2007. 370(9583): p. 263-271.

8. Nestle, F., D. Kaplan, and M. Schon, Barker J: Psoriasis. N Engl J Med, 2009. 361(17): p. 496-509.

9. Ayala-Fontánez, N., D.C. Soler, and T.S. McCormick, Current knowledge on psoriasis and autoimmune diseases. Psoriasis (Auckland, NZ), 2016. 6: p. 7.

10. Wu, Y., D. Mills, and M. Bala, Psoriasis: cardiovascular risk factors and other disease comorbidities. Journal of drugs in dermatology: JDD, 2008. 7(4): p. 373-377.

11. Erickson, K.L. and N.E. Hubbard, Probiotic immunomodulation in health and disease. The Journal of nutrition, 2000. 130(2): p. 403S-409S.

12. Both, H., et al., Critical review of generic and dermatology-specific health-related quality of life instruments. Journal of Investigative Dermatology, 2007. 127(12): p. 2726-2739.

13. Langley, R.G. and C.N. Ellis, Evaluating psoriasis with psoriasis area and severity index, psoriasis global assessment, and lattice system physician's global assessment. Journal of the American Academy of Dermatology, 2004. 51(4): p. 563-569.

14. Mattei, P., K. Corey, and A. Kimball, Psoriasis Area Severity Index (PASI) and the Dermatology Life Quality Index (DLQI): the correlation between disease severity and psychological burden in patients treated with biological therapies. Journal of the European Academy of Dermatology and Venereology, 2014. 28(3): p. 333-337. 
15. Unaeze, J., et al., Impact of psoriasis on health-related quality of life decreases over time: an 11-year prospective study. Journal of Investigative Dermatology, 2006. 126(7): p. 1480-1489.

16. Moludi, J., et al., The Effect of Probiotic Supplementation on Depressive Symptoms and Quality of Life in Patients After Myocardial Infarction: Results of a Preliminary Double-Blind Clinical Trial. Psychosomatic medicine, 2019. 81(9): p. 770-777.

17. Nobutani, K., et al., The effects of administration of the Lactobacillus gasseri strain CP 2305 on quality of life, clinical symptoms and changes in gene expression in patients with irritable bowel syndrome. Journal of applied microbiology, 2017. 122(1): p. 212-224.

18. Sarkar, A., et al., Psychobiotics and the manipulation of bacteria-gut-brain signals. Trends in neurosciences, 2016. 39(11): p. 763-781.

19. Valles-Colomer, M., et al., The neuroactive potential of the human gut microbiota in quality of life and depression. Nature microbiology, 2019. 4(4): p. 623-632.

20. Groeger, D., et al., Bifidobacterium infantis 35624 modulates host inflammatory processes beyond the gut. Gut microbes, 2013. 4(4): p. 325-339.

21. Parodi, A., et al., Small intestinal bacterial overgrowth in rosacea: clinical effectiveness of its eradication. Clinical Gastroenterology and Hepatology, 2008. 6(7): p. 759-764.

22. Caiazzo, G., et al., Psoriasis, cardiovascular events, and biologics: lights and shadows. Frontiers in immunology, 2018. 9: p. 1668.

23. Samarasekera, E.J., et al., Incidence of cardiovascular disease in individuals with psoriasis: a systematic review and meta-analysis. Journal of Investigative Dermatology, 2013. 133(10): p. 23402346.

24. Boehncke, W.-H., Systemic inflammation and cardiovascular comorbidity in psoriasis patients: causes and consequences. Frontiers in immunology, 2018. 9: p. 579.

25. Eder, L. and D.D. Gladman, Atherosclerosis in psoriatic disease: latest evidence and clinical implications. Therapeutic advances in musculoskeletal disease, 2015. 7(5): p. 187-195.

26. Chen, Y.-H., et al., Lactobacillus pentosus GMNL-77 inhibits skin lesions in imiquimod-induced psoriasis-like mice. Journal of food and drug analysis, 2017. 25(3): p. 559-566.

27. Nermes, M., et al., Interaction of orally administered Lactobacillus rhamnosus GG with skin and gut microbiota and humoral immunity in infants with atopic dermatitis. Clinical \& Experimental Allergy, 2011. 41(3): p. 370-377.

28. Alesa, D.I., et al., The role of gut microbiome in the pathogenesis of psoriasis and the therapeutic effects of probiotics. Journal of Family Medicine and Primary Care, 2019. 8(11): p. 3496.

29. Vijayashankar, M. and N. Raghunath, Pustular psoriasis responding to probiotics-A new insight. Our Dermatology Online, 2012. 3(4): p. 326.

\section{Figures}




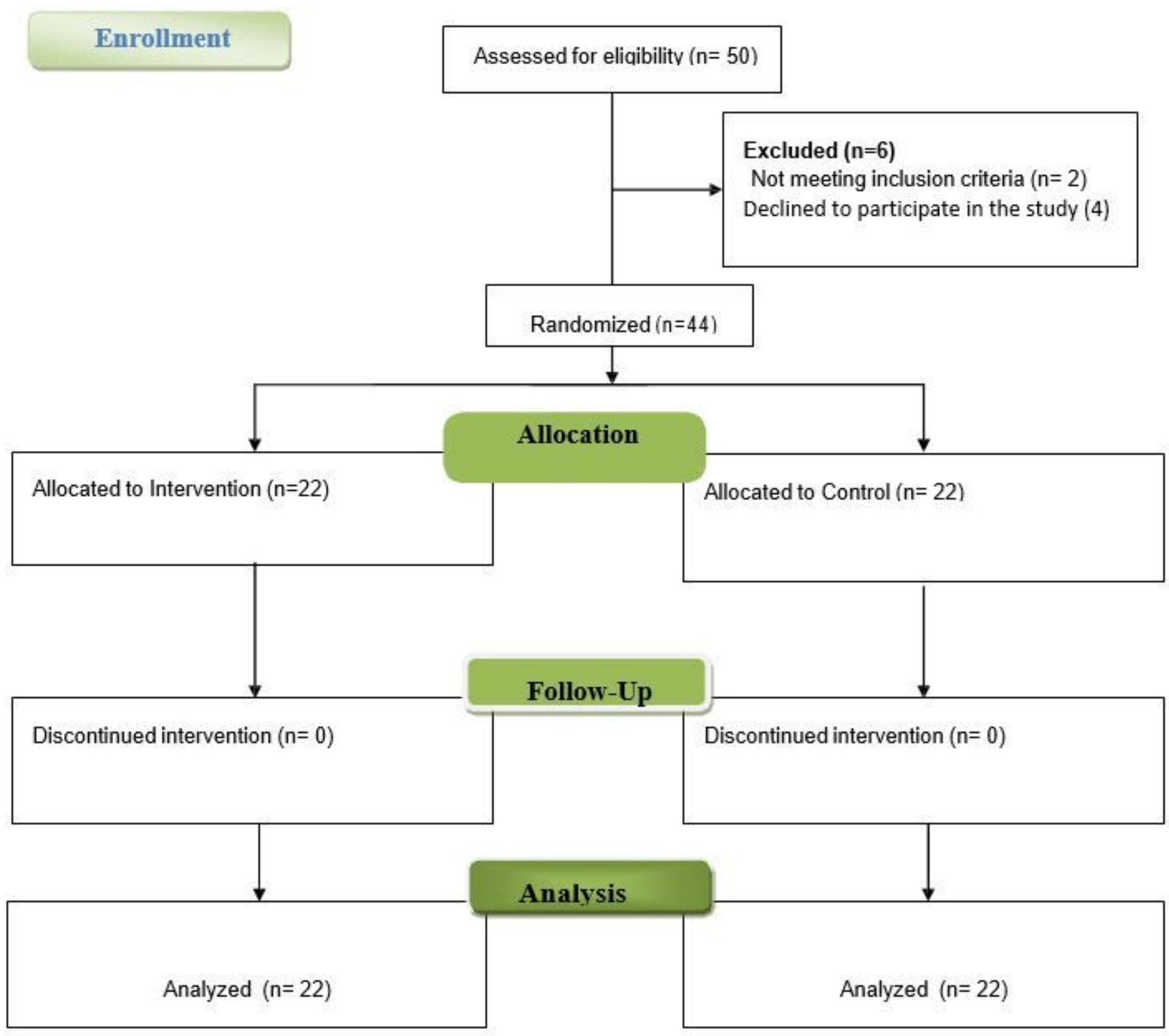

Figure 1

CONSORT diagram 


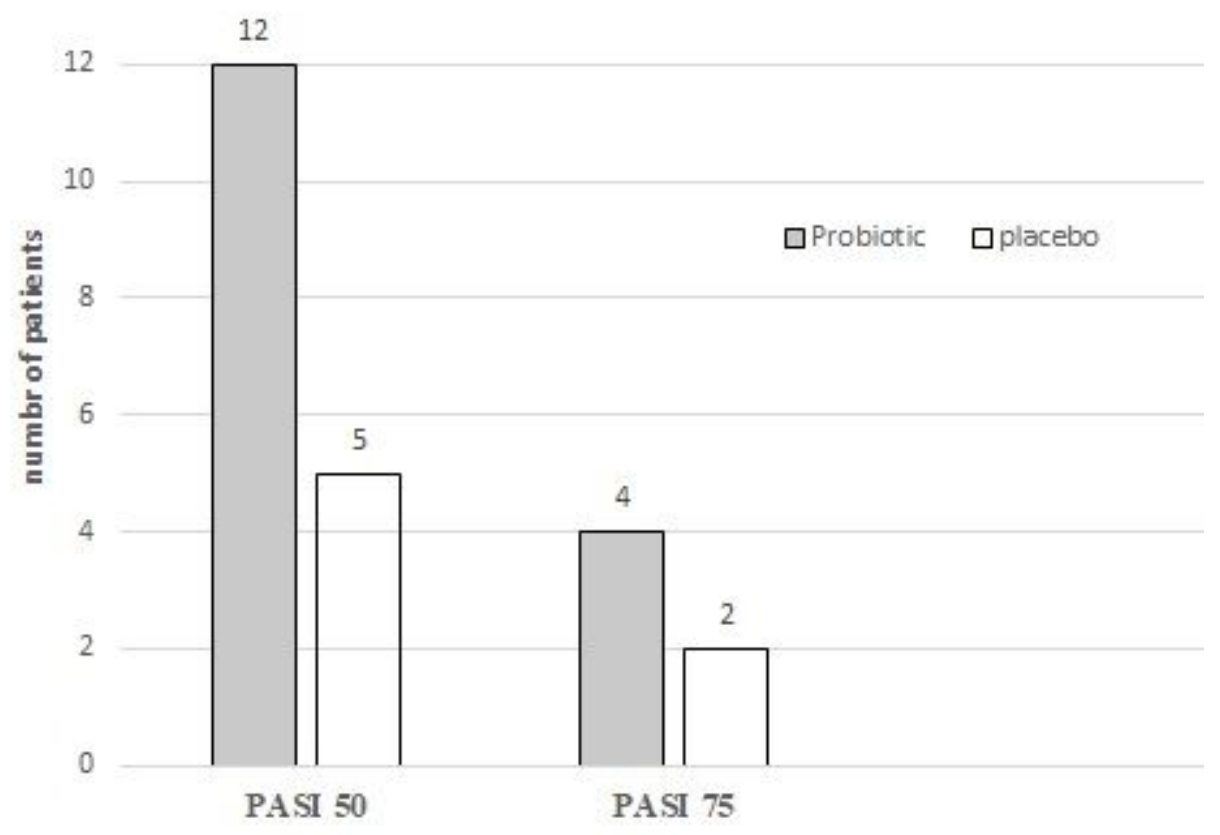

Figure 2

Figure 2

Page 18/19 


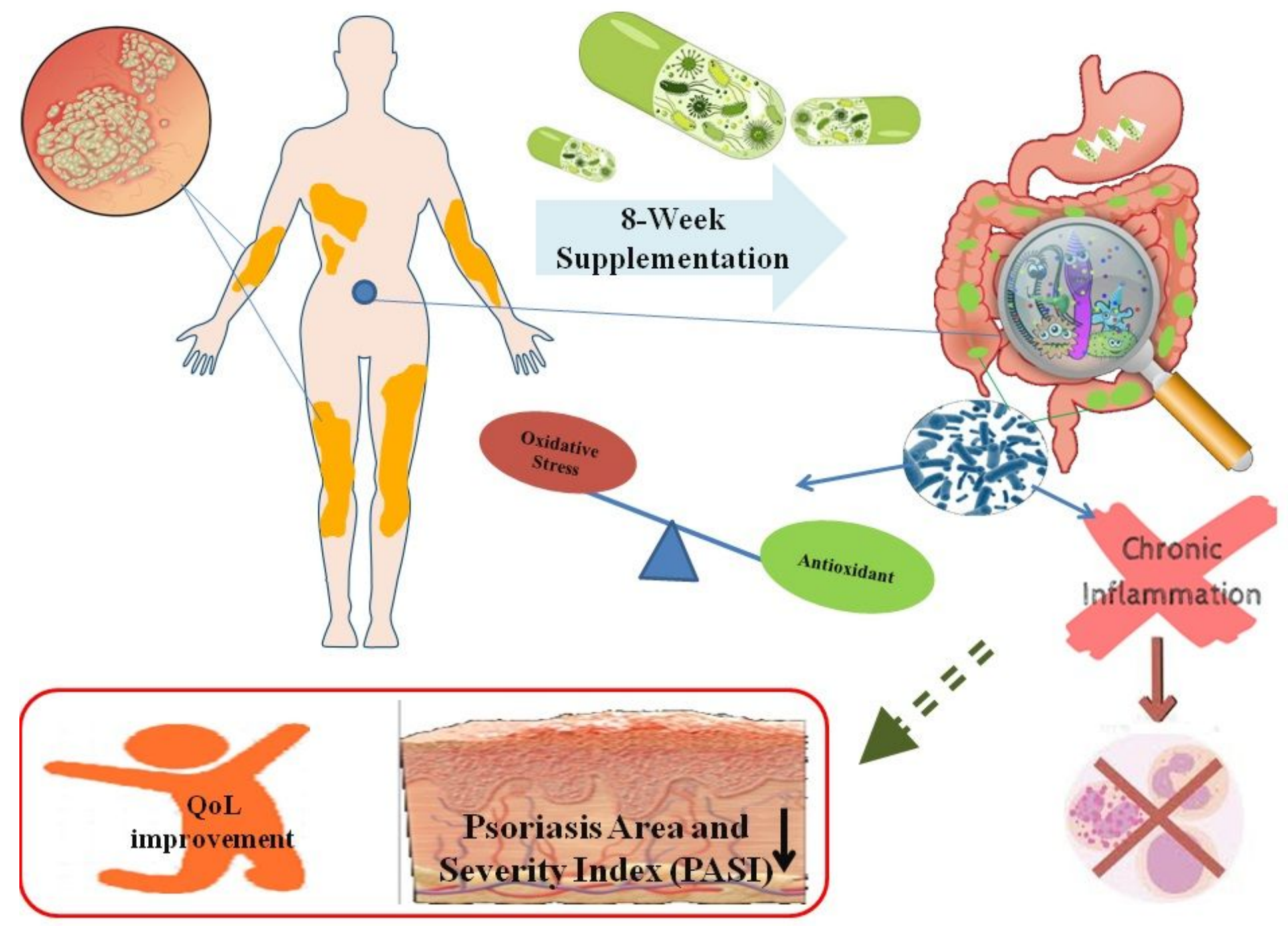

Figure 3

Figure 3 